\title{
Association of aortic stiffness with cognitive decline: Whitehall II longitudinal cohort study
}

\author{
Marzieh Araghi ${ }^{1} \cdot$ Martin J. Shipley ${ }^{1} \cdot$ Ian B. Wilkinson ${ }^{2} \cdot$ Carmel M. McEniery $^{2} \cdot$ Carlos A. Valencia-Hernández ${ }^{1}$. \\ Mika Kivimaki $^{1} \cdot$ Séverine Sabia ${ }^{1,3} \cdot$ Archana Singh-Manoux $^{1,3} \cdot$ Eric J. Brunner $^{1}$
}

Received: 23 August 2019 / Accepted: 13 November 2019 / Published online: 27 November 2019

(c) The Author(s) 2019

\begin{abstract}
Aortic stiffness is associated with an increased risk of cardio- and cerebrovascular disease and mortality and may increase risk of dementia. The aim of the present study is to examine the association between arterial stiffness and cognitive decline in a large prospective cohort study with three repeated cognitive assessment over 7 years of follow-up. Aortic pulse wave velocity (PWV) was measured among 4300 participants (mean \pm standard deviation age 65.1 \pm 5.2 years) in 2007-2009 and categorized based on the tertiles: (lowest third: $<7.41 \mathrm{~m} / \mathrm{s}$ ), (middle third: $7.41-8.91 \mathrm{~m} / \mathrm{s}$ ), and (highest third: $>8.91 \mathrm{~m} / \mathrm{s}$ ). A global cognitive score was calculated in 2007-2009, 2012-2013, and 2015-2016 based on responses to memory, reasoning and fluency tests. Standardized global cognitive score $(m e a n=0, S D=1)$ in highest third versus lowest third of PWV category was lower at baseline $(-0.12,95 \%$ CI $-0.18,-0.06)$. Accelerated 7 -year cognitive decline was observed among individuals with the highest PWV [difference in 7-year cognitive change for highest third versus lowest third PWV: -0.06 , $95 \% \mathrm{CI}-0.11,-0.01, P<0.01]$. Higher aortic stiffness was associated with faster cognitive decline. Clinicians may be able to use arterial stiffness severity as an indicator to administer prompt treatments to prevent or delay the onset of cognitive decline or dementia. Future studies need to determine whether early intervention of vascular stiffness is effective in delaying these outcomes.
\end{abstract}

Keywords Ageing $\cdot$ Arterial stiffness $\cdot$ Cognitive decline $\cdot$ Pulse-wave velocity

\section{Introduction}

The substantial expansion in life expectancy and population ageing is a major achievement but also one of the 21st century public health challenges. Ageing is associated with exponential increases in number of people living with cognitive impairment and dementia, both of which reduce quality

Electronic supplementary material The online version of this article (https://doi.org/10.1007/s10654-019-00586-3) contains supplementary material, which is available to authorized users.

Marzieh Araghi

m.araghi@ucl.ac.uk

1 Department of Epidemiology and Public Health, University College London, 1-19 Torrington Place, London WC1E 6BT, UK

2 Division of Experimental Medicine and Immunotherapeutics, University of Cambridge, Cambridge, UK

3 Inserm U1153, Epidemiology of Ageing and Neurodegenerative Diseases, Paris, France of life [1, 2]. The number of people with dementia is projected to increase from $0.7 \mathrm{M}$ in 2016 to $1.2 \mathrm{M}$ by 2040 in England and Wales [3].

Aortic stiffness, due to loss of elasticity of the artery wall, increases with age and risk factor exposure [4-7] is associated with higher systolic, pulse pressure and atherosclerosis [8], which are in turn important predictors of cardio- and cerebrovascular morbidity and mortality as well as predictors of cognitive decline [9]. The links between cardiovascular disorders and cognitive decline and dementia remain unclear. If such vascular pathophysiological alterations are better understood, it may be possible to prevent or delay cognitive decline and improve quality of life in older people.

Aortic pulse wave velocity (PWV) is the non-invasive gold standard to determine arterial stiffness [10]. Smallscale observational studies (eight cross-sectional studies and five prospective cohort studies) [11-23] have assessed the association of arterial stiffness with cognitive impairment, but their results are inconsistent. It was suggested that arterial stiffness may influence specific cognitive domains 
such as executive function [11, 20], memory [18, 19, 22], and processing speed [11]. Longitudinal cognitive test data spanning a decade were rare, with small sample size and may have biases attributable to selective attrition (leading to younger persons with better cognitive function over-represented at follow-up). This limits interpretation of previous studies. Further, cognitive function was mainly assessed with the Mini-Mental State Examination (MMSE), a global test with low sensitivity for detection of small changes in cognitive status [24].

Our study is the first longitudinal study with a sensitive cognitive measure (cognitive test battery), large sample size, and high response rate for all three measures of cognitive function (Phases 9, 11, and 12) to examine whether arterial stiffness is associated with deficits and changes in specific cognitive domains. In addition, risk of attrition bias was controlled for using inverse probability weighting to account for missing data over the follow-up period. We hypothesized that higher PWV would be associated with both concurrently assessed cognitive performance and subsequent cognitive decline. We examined a global measure of cognitive function, and the cognitive domains of memory, executive function and verbal fluency using data on 4300 individuals.

\section{Methods}

\section{Study population}

The Whitehall II study is a longitudinal cohort study, initially of 10,308 (67\% men, aged 35-55 years) London-based British civil servants, recruited in 1985 . Since then, followup questionnaire surveys and clinical examinations have taken place every $2-3$ years and 5 years, respectively. Ethical approval for each study phase was obtained from the NHS National Research Ethics Service and the local Research Ethics Committee. All participants provided written consent prior to each study phase.

The 2007-2009 clinical examination was attended by 6225 participants. Of these, 4300 participants provided data on both PWV and cognitive function, forming the analytic sample to examine the association between PWV and cognitive trajectories (Fig. 1). The association between PWV and "pronounced cognitive decline" was assessed in analysis based on 3828 participants.

\section{Aortic PWV}

PWV was assessed between the carotid and femoral sites using applanation tonometry (SphygmoCor, Atcor Medical, Australia), a validated method of measuring PWV. Path length was determined with a tape measure by subtracting the carotid-sternal notch distance from the femoral-sternal notch distance. PWV was measured twice for each participants and a third measurement was taken when the difference between the two measurements were larger than $0.5 \mathrm{~m} / \mathrm{s}$. The average of all the measurements was used in the analysis. PWV measurements were repeated within 60 days for 125 participants to assess short-term repeatability. Median difference of the repeats were $0.83 \mathrm{~m} / \mathrm{s}$ (interquartile range 0.43-1.40).

\section{Cognitive function}

The cognitive test battery was administered at the clinical examinations in 2007-2009, 2012-2013, and 2015-2016. Test-retest reliability was assessed in 556 participants within 3 months and showed excellent reliability (range 0.6-0.9). The cognitive tests were as follows. Memory: participants were presented with a 20 -word list of one or two syllable words at two second intervals, with 2 min time to write down as many words as they can recall, regardless of word order. Reasoning: participants had $10 \mathrm{~min}$ to complete the AH4-I (Alice Heim 4-I), a series of 65 verbal and mathematical reasoning items of increasing difficulty. Verbal Fluency: phonemic fluency was assessed via the "S" words and semantic fluency via "animal" words tests. One minute was allowed for each test. To reduce measurement error and ease comparison between tests with different score ranges, we standardized all raw test scores for these four measures to $\mathrm{z}$-scores $($ mean $=0$, standard deviation $[\mathrm{SD}]=1$ ) and summed and re-standardized the scores to yield a global cognitive score, as in previous studies [25, 26]. The 30-item Mini-Mental-State-Examination (MMSE) was also used in supplementary analyses, as an alternative measure, to assess global cognitive status.

\section{Baseline characteristics}

Sociodemographic variables included age, sex, ethnicity (white, others), socioeconomic status using employment grade (three categories: high, intermediate, and low representing income and status at work), and education (five categories: less than primary school (up to age 11), lower secondary school (up to age 16), higher secondary school (up to age 18), university, and higher university degree).

Health behaviors were assessed by questionnaire and included smoking (current smokers, ex-smokers, and never smokers) and, alcohol consumption (number of alcoholic drinks consumed in the previous days, converted to units of alcohol consumed in a week and categorized as "no/occasional alcohol consumption," "moderate alcohol consumption" (1-14 units/week), and "heavy alcohol consumption" ( $\geq 14$ units/week)).

Health related covariates included body mass index assessed at the clinical examination (categorized as $<20$, 


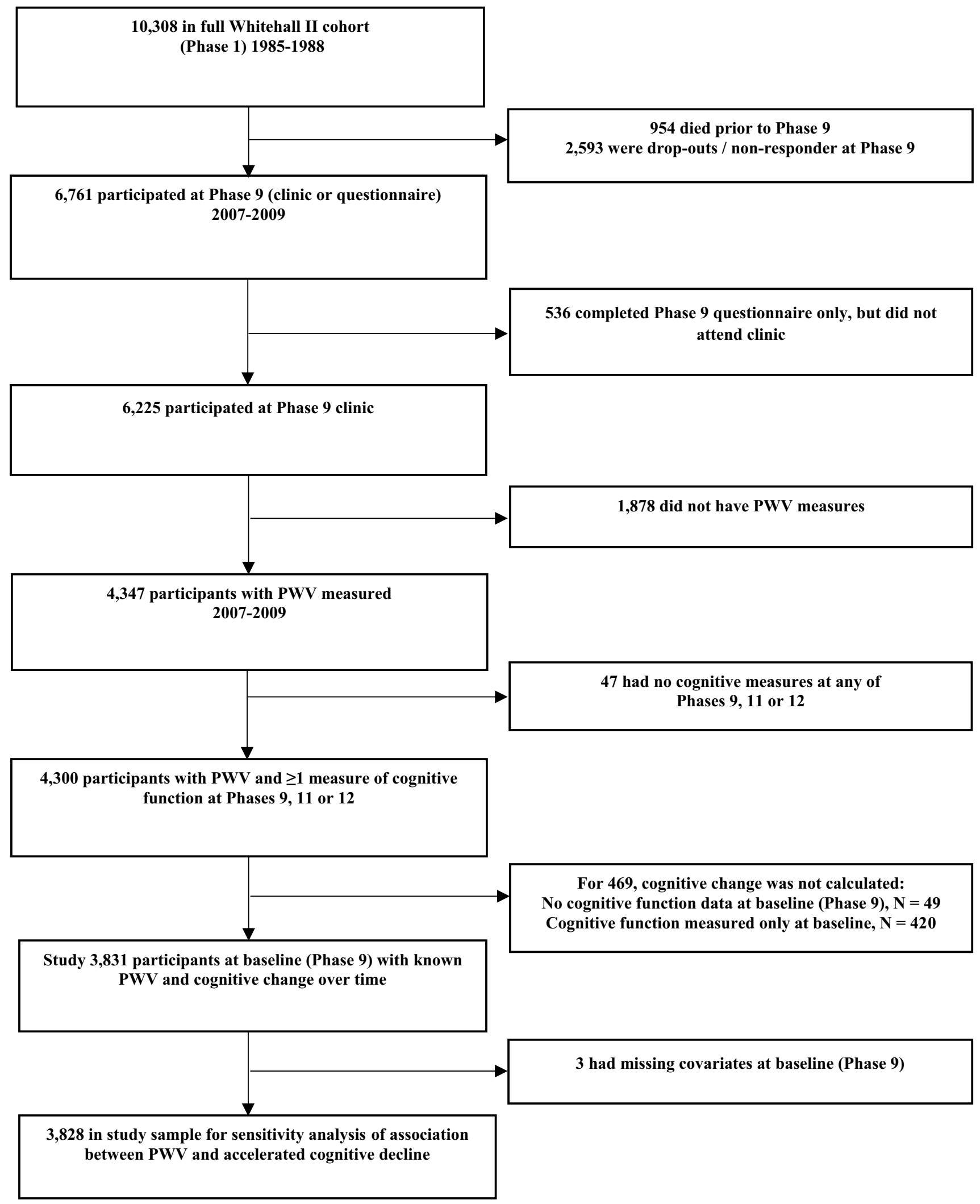

Fig. 1 Study flowchart 
20-24.9, 25-29.9, and $\geq 30 \mathrm{~kg} / \mathrm{m}^{2}$ ), hypertension (systolic/ diastolic blood pressure $\geq 140 / 90 \mathrm{~mm} \mathrm{Hg}$ or use of antihypertensive drugs), self-reported use of drugs, prevalent diabetes mellitus (determined by fasting glucose $\geq 7.0 \mathrm{mmol} / \mathrm{L}$, reported diabetes diagnosed by a doctor, or use of diabetes drugs), and cardiovascular diseases (CVD) (including coronary heart disease and stroke (identified using linkage to national hospital records)).

\section{Statistical analysis}

Linear mixed models were used to estimate both the crosssectional and the longitudinal association of PWV with the global cognitive score. These methods use all available cognitive data over the three measures and take into account the fact that repeated measures on the same individual are correlated with each other. The intercept and the slope were fitted as random effects, allowing individuals to have different cognitive scores at baseline and different rates of cognitive decline over the follow-up. The PWV distribution was categorized into thirds: (lowest third: $<7.41 \mathrm{~m} / \mathrm{s}$ ), (middle third: $7.41-8.91 \mathrm{~m} / \mathrm{s}$ ), and (highest third: $>8.91 \mathrm{~m} / \mathrm{s}$ ).

We then fitted the mixed models using these categories of PWV with global cognitive score and also for each cognitive domain as the dependent variable. Since the mean follow-up (time between the first and last cognitive measure) was 7.3 years, we expressed the changes in the cognitive measures per 7 years. The PWV $\times$ time $\times$ sex interactions suggested no sex differences in the PWV associations with cognitive function or with cognitive decline (all $P>0.14$ ) and, therefore, all analyses were conducted with men and women combined. All analyses were adjusted for sex, age, ethnicity and employment grade by fitting these terms and their interactions with follow-up time. Please see the supplementary materials (Model specification) for the full model specification. We also used MMSE $<27$ and MMSE $<26$ as two ways to define those with cognitive decline and fitted mixed logistic models with these two outcomes, adjusting for age, sex, ethnicity and employment grade, as above. We conducted a sensitivity analysis to assess the potential bias caused by selective attrition over the follow-up period by refitting the models using generalized estimating equations and using inverse probability weights for each observation [27]. The inverse probability weights were obtained by using the 6225 individuals who participated at the Phase 9 clinic and fitting three logistic models to predict which individuals were included in the analysis at Phases 9, 11 and 12 respectively. These logistic models used covariates ascertained at Phase 9 where possible and included sociodemographic factors (age, sex, ethnicity, marital status and employment grade), behavioral factors (smoking status, alcohol consumption and level of physical activity), chronic conditions (coronary heart disease, stroke and diabetes), cardiometabolic risk factors (body mass index, systolic and diastolic blood pressure and serum cholesterol), mental health (General Health Questionnaire caseness) and medication use (antihypertensive and lipid lowering).

In order to assess the robustness of the association between PWV and cognition, we examined whether PWV was a predictor of which individuals had the most pronounced cognitive decline. A linear mixed model was first used to estimate the decline in global cognitive score across the three waves of data collection for each participant. A binary outcome variable was then created to indicate the $20 \%$ of participants with the fastest cognitive declines compared to those of similar age, sex and employment grade. This was achieved by creating twenty-four 5-year age group by sex by employment grade strata and selecting the $20 \%$ of participants with the fastest cognitive declines within each of these strata. Logistic regression models were fitted and odds ratios (ORs) and corresponding 95\% confidence intervals (95\% CIs) calculated to estimate the association between PWV and the fastest rate of cognitive decline. These models were adjusted for sex, age, ethnicity and employment grade to ensure that there was no residual confounding from these covariates. A sensitivity analysis was conducted to assess the robustness of the estimates to using a different range of thresholds (10-25\%) for the proportion of participants with the fastest cognitive decline. Statistical significance was inferred as a two-tailed $P$ value $<0.05$.

The figure showing the global cognitive score trajectories with time was produced using StataSE 15.1. All other models were fitted using the Proc Mixed, Proc Glimmix and Proc Genmod procedures from the SAS software version 9.4 (SAS Institute, Cary, NC, USA).

\section{Results}

Figure 1 shows the number eligible participants included in the analysis. Of the 10,308 participants at study inception (1985-1988), 954 had died, 2593 had withdrawn from the study, and 536 did not attend clinic in 2007-2009. Our first analysis was based on 4300 of the 6225 individuals still in the study. Those included in the analyses were more educated ( $40 \%$ vs. $32 \%$ had a university degree, $P<0.001$ ), were younger (65 years vs. 67 years, $P<0.001$ ) and generally had a healthier risk factor profile than those excluded (Supplementary Table 1). Demographic and clinical characteristics at baseline among those included in the analyses are shown in Table 1 according to the thirds of PWV. Participants in the highest third were older and had a more adverse risk factor profile than those in the lowest third.

Cross-sectional and longitudinal associations between PWV and global cognitive score and individual cognitive domains, are shown in Table 2. In the cross-sectional 
Table 1 Baseline characteristics of 4300 participants in the study sample according to the thirds of pulse wave velocity

\begin{tabular}{|c|c|c|c|c|}
\hline & \multicolumn{3}{|l|}{ [Mean (SD) or \%] } & \multirow{3}{*}{$\begin{array}{l}P \text { value for } \\
\text { heterogeneity }\end{array}$} \\
\hline & \multicolumn{3}{|c|}{ Thirds of baseline pulse wave velocity $(\mathrm{m} / \mathrm{s})$} & \\
\hline & Lowest third $(<7.41)$ & $\begin{array}{l}\text { Middle third } \\
(7.41-8.91)\end{array}$ & Highest third $(>8.91)$ & \\
\hline Number & 1436 & 1438 & 1426 & \\
\hline Age (y) & $63.1(4.9)$ & $64.8(5.5)$ & $68.0(5.6)$ & $<0.001$ \\
\hline Female $(\%)$ & 28.9 & 25.1 & 21.7 & $<0.001$ \\
\hline Non-white ethnicity (\%) & 5.6 & 6.9 & 10.4 & $<0.001$ \\
\hline Body mass index $\left(\mathrm{kg} / \mathrm{m}^{2}\right)$ & & & & $<0.001$ \\
\hline Underweight $(<18.5)$ & 1.1 & 0.6 & 0.9 & \\
\hline Normal weight (18.5-24.9) & 50.1 & 37.1 & 32.7 & \\
\hline Overweight (25.0-29.9) & 37.7 & 47.3 & 48.2 & \\
\hline Obese $(\geq 30.0)$ & 10.4 & 15.0 & 18.2 & \\
\hline Systolic blood pressure (mm Hg) & $117.6(13.4)$ & $124.0(13.9)$ & $132.0(15.5)$ & $<0.001$ \\
\hline Diastolic blood pressure (mm Hg) & $67.5(9.4)$ & $71.0(9.5)$ & $73.5(10.3)$ & $<0.001$ \\
\hline Anti-hypertension medication (\%) & 23.6 & 32.9 & 41.6 & $<0.001$ \\
\hline Serum cholesterol (mmol/L) & $5.28(1.03)$ & $5.19(1.04)$ & $5.17(1.09)$ & 0.009 \\
\hline Lipid lowering medication (\%) & 23.3 & 32.0 & 36.6 & $<0.001$ \\
\hline Education & & & & $<0.001$ \\
\hline$\leq$ Lower secondary & 26.4 & 32.7 & 36.9 & \\
\hline Higher secondary & 29.5 & 28.1 & 26.6 & \\
\hline$\geq$ Degree & 44.1 & 39.2 & 36.5 & \\
\hline Employment grade & & & & 0.04 \\
\hline High & 51.9 & 49.3 & 48.2 & \\
\hline Intermediate & 40.7 & 42.5 & 41.5 & \\
\hline Low & 7.4 & 8.2 & 10.3 & \\
\hline Smoking habit & & & & 0.03 \\
\hline Never & 51.4 & 47.3 & 48.6 & \\
\hline Ex-smoker & 43.4 & 47.0 & 47.5 & \\
\hline Current & 5.2 & 5.8 & 3.9 & \\
\hline Alcohol consumption & & & & $<0.001$ \\
\hline No alcohol & 14.5 & 17.1 & 17.6 & \\
\hline Moderate alcohol & 71.7 & 65.3 & 64.2 & \\
\hline Heavy alcohol & 13.8 & 17.6 & 18.1 & \\
\hline Moderate or vigorous physical activity & & & & 0.01 \\
\hline$<1 \mathrm{~h} / \mathrm{wk}$ & 19.3 & 23.4 & 23.2 & \\
\hline $1-6.9 \mathrm{~h} / \mathrm{wk}$ & 61.7 & 59.7 & 61.3 & \\
\hline$\geq 7 \mathrm{~h} / \mathrm{wk}$ & 19.0 & 17.0 & 15.5 & \\
\hline Diabetes (\%) & 5.9 & 9.5 & 18.5 & $<0.001$ \\
\hline History of cardiovascular disease (\%) & 9.6 & 10.8 & 14.7 & $<0.001$ \\
\hline
\end{tabular}

analysis, global cognitive score was significantly lower in the middle third and the highest third of PWV $(>8.91 \&$ $7.41-8.91 \mathrm{~m} / \mathrm{s})$ compared to the lowest third $(<7.41 \mathrm{~m} / \mathrm{s})$. A cross-sectional association was seen for the highest third with all cognitive domains $(P<0.05)$, compared to the lowest third. In the longitudinal analysis, global cognitive function declined significantly faster in the highest third compared to the lowest third after adjustment for age, sex, ethnicity and employment grade [difference in 7-year change in score for $>8.91 \mathrm{~m} / \mathrm{s}$ versus $<7.41 \mathrm{~m} / \mathrm{s}=-0.06(-0.11$ to $-0.01), P=0.01]$. Similar effects were seen for some of the cognitive domains but only with phonemic fluency the association was statistically significant $(P=0.03)$. The estimates changed little when the analyses were repeated using inverse probability weights to allow for potential selection bias with the cross-sectional effects being slightly strengthened and the longitudinal effects marginally weakened (Supplementary Table 2). The cross-sectional estimate of the highest 
Table 2 Cross-sectional and longitudinal association between the thirds of pulse wave velocity and standardized scores of global cognitive score and individual cognitive domains

\begin{tabular}{|c|c|c|c|c|c|}
\hline \multirow{2}{*}{$\begin{array}{l}\text { Cognitive } \\
\text { domain out- } \\
\text { come }\end{array}$} & \multirow[t]{2}{*}{ Pulse wave velocity } & \multicolumn{2}{|c|}{$\begin{array}{l}\text { Standardized cognitive score at } \\
\text { baseline }\end{array}$} & \multicolumn{2}{|c|}{$\begin{array}{l}\text { Change in standardized cogni- } \\
\text { tive score (per } 7 \text { years) }\end{array}$} \\
\hline & & Difference $^{\mathrm{a}}(95 \% \mathrm{CI})$ & $P$ value & Difference $^{\mathrm{a}}(95 \% \mathrm{CI})$ & $P$ value \\
\hline \multicolumn{6}{|c|}{ Global cognitive score } \\
\hline & Lowest third & 1.0 (Ref) & - & 1.0 (Ref) & - \\
\hline & Middle third & $-0.06(-0.12,-0.01)$ & 0.03 & $-0.02(-0.06,0.03)$ & 0.48 \\
\hline & Highest third & $-0.12(-0.18,-0.06)$ & $<0.001$ & $-0.06(-0.11,-0.01)$ & 0.01 \\
\hline \multicolumn{6}{|l|}{ Memory } \\
\hline & Lowest third & 1.0 (Ref) & - & 1.0 (Ref) & - \\
\hline & Middle third & $-0.04(-0.10,0.03)$ & 0.28 & $0.04(-0.03,0.11)$ & 0.23 \\
\hline & Highest third & $-0.12(-0.19,-0.05)$ & $<0.001$ & $-0.01(-0.08,0.07)$ & 0.84 \\
\hline \multicolumn{6}{|l|}{ AH4-I } \\
\hline & Lowest third & $1.0(\operatorname{Ref})$ & - & $1.0(\operatorname{Ref})$ & - \\
\hline & Middle third & $-0.06(-0.12,0.00)$ & 0.03 & $0.01(-0.02,0.05)$ & 0.52 \\
\hline & Highest third & $-0.08(-0.13,-0.02)$ & 0.01 & $-0.03(-0.07,0.01)$ & 0.09 \\
\hline \multicolumn{6}{|c|}{ Phonemic fluency } \\
\hline & Lowest third & 1.0 (Ref) & - & 1.0 (Ref) & - \\
\hline & Middle third & $-0.08(-0.15,-0.01)$ & 0.02 & $-0.03(-0.09,0.04)$ & 0.45 \\
\hline & Highest third & $-0.10(-0.17,-0.03)$ & 0.007 & $-0.08(-0.15,-0.01)$ & 0.03 \\
\hline \multicolumn{6}{|c|}{ Semantic fluency } \\
\hline & Lowest third & 1.0 (Ref) & - & $1.0(\operatorname{Ref})$ & - \\
\hline & Middle third & $-0.02(-0.09,0.04)$ & 0.45 & $-0.05(-0.11,0.00)$ & 0.06 \\
\hline & Highest third & $-0.08(-0.14,-0.01)$ & 0.03 & $-0.06(-0.13,0.00)$ & 0.06 \\
\hline
\end{tabular}

${ }^{a}$ Differences are adjusted for age and sex and their interactions with time and time squared and for ethnicity and employment grade and their interactions with time third of PWV increased by less than $1 \%$ when the 5 prevalent dementia cases were excluded and the longitudinal effect of the highest third of PWV on cognitive function was reduced by $5 \%$ when the 10 incident cases of dementia were excluded from the analysis. When participants with a history of CVD were excluded from the analyses, the cross-sectional estimate of the highest third of PWV was reduced by $11 \%$ but remained statistically significant $(P=0.002)$, and the longitudinal effect was reduced by $4 \%$ and remained statistically significant $(P=0.03)$. When we adjusted for cholesterol levels, the cross-sectional estimate of the highest (vs. lowest) third of PWV decreased by $11 \%$ and the longitudinal estimate decreased by $2 \%$.

The declines in global cognitive score with time, after adjustment for sex, ethnicity and employment grade, are shown for the three PWV categories in Fig. 2. The global cognitive scores decrease fastest for those in the highest third of PWV such that the difference between the highest and lowest third of PWV after 7 years is $50 \%$ greater than at baseline $(-0.18$ vs. -0.12$)$. We assessed the association between MMSE and PWV, both cross-sectionally and longitudinally and the results were not significant (Supplementary Table 3).

In the analyses to predict those with the fastest cognitive declines as the outcome (binary variable of top $20 \%$

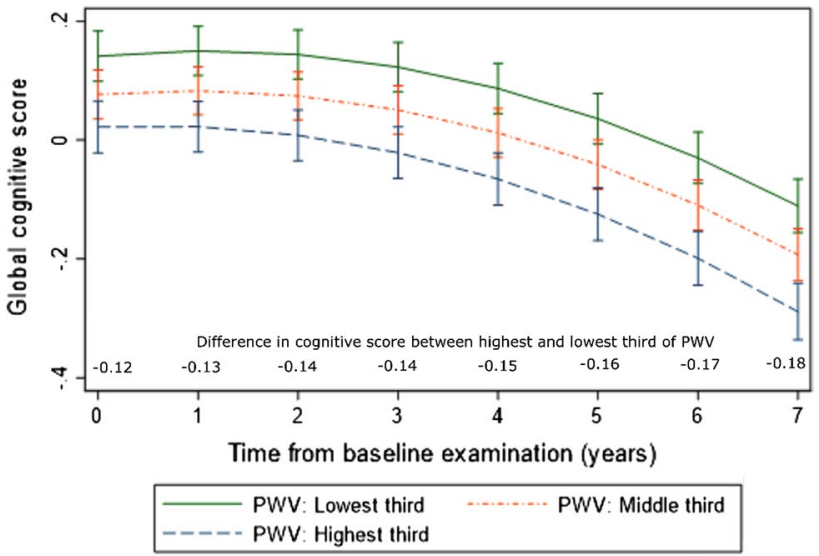

Fig. 2 Trajectories (The trajectories of global cognitive score are the predicted values that come from the mixed model that was used to estimate the effects of pulse wave velocity on global cognitive function shown in Table 2) of global cognitive score with follow-up time from baseline examination according to thirds of pulse wave velocity

vs. rest), individuals in the highest third of PWV were $40 \%$ more likely to exhibit rapid declines in cognitive function during prospective follow-up (OR 1.40, 95\% CI: 1.13, 1.73), following adjustment for age, sex, ethnicity and employment grade (Table 3). Excluding 4 participants who had prevalent 
Table 3 Association between pulse wave velocity and accelerated global cognitive decline during follow-up

\begin{tabular}{lllc}
\hline Pulse wave velocity & No. participants & $\begin{array}{l}\text { The } 20 \% \text { of participants with the greatest cogni- } \\
\text { tive decline over the follow-up, N (\%) }\end{array}$ & Odds ratio $^{\mathrm{b}}$ (95\% CI) $P$ value \\
\hline Lowest third & 1316 & $224(17.2 \%)$ & $1.0($ Ref $)$ \\
Middle third & 1300 & $265(20.4 \%)$ & $1.23(1.01,1.51) 0.04$ \\
Highest third & 1212 & $281(23.2 \%)$ & $1.40(1.13,1.73) 0.002$ \\
Effect per 1 SD increase & 3828 & $770(20.1 \%)$ & $1.11(1.02,1.21) 0.02$ \\
\hline
\end{tabular}

${ }^{\text {a }}$ The cut-points for those with the greatest cognitive decline are age, sex and employment grade specific and are based upon the 3828 participants in this analysis

${ }^{\mathrm{b}}$ Odds ratios of being in the group with the greatest cognitive decline are adjusted for age, sex, ethnicity and employment grade

dementia and 10 who had dementia diagnosed during the follow-up made little impact and the coefficient for PWV was reduced by less than $1 \%$. Further sensitivity analyses assessing different percentages $(10,15,20$, and $25 \%)$ of participants with the fastest cognitive declines were broadly consistent with the main findings (Supplementary Table 4).

\section{Discussion}

Aortic stiffness was associated with faster global cognitive decline over seven years of follow-up. Individuals in the highest third of PWV compared to the lowest had $40 \%$ higher odds of cognitive decline. We aimed to identify whether specific cognitive domains contributed to the global decline, but no robust association between arterial stiffness and cognitive decline in all cognitive domains were observed. Decline in phonemic fluency was most clearly associated with aortic stiffness, while decline in reasoning capacity assessed by the AH4-I was linked with aortic stiffness only marginally.

Although several studies [11-20] have identified an inverse association between aortic stiffness and cognition, a few studies [21-23] did not find an association. Our large longitudinal study adds to the evidence that aortic stiffness predicts cognitive decline. Several proposed pathways link aortic stiffness to cognitive decline. First, the stiff aorta loses its cushioning capacity and promotes transmission of potentially deleterious central pressure pulses to the fragile small vessels of target organs such as the brain. Increased pulsatile flow in the brain may accelerate intracranial stenosis, and dysfunction in the cerebral microcirculation [28, 29]. Second, chronic cerebral hypoperfusion may induce cerebral white matter injury or lead to toxic metabolic byproducts accumulation within the brain and blood vessels [30]. Moreover, thrombosis and microinfarcts that can be caused as a result of thickening of the cerebrovascular endothelium and associated endothelial dysfunction are also apparent in malignant hypertension [31]. Third, arterial stiffness is associated with the risk of developing stroke [32] and it has been confirmed that stroke could result in the cognitive impairment [33].

Previously, a study reported concurrent decline in both phonemic and sematic fluency in a group of people with mild cognitive impairment (MCI) [34], while another study [35] showed that individuals with MCI performed worse on phonemic fluency than sematic fluency. While the underlying mechanisms remained largely unknown, evidence shows that multiple brain regions involves during fluency tasks, phonemic fluency tasks are proposed to rely mainly upon executive functioning and pre-frontal lobe processes, whereas sematic fluency tasks are proposed to rely on temporal lobe process [36]. The findings of present study support the hypothesis that aortic stiffness is linked to cognitive decline mediated by frontal lobe atrophy as a result of small vessel disease.

Our findings were in accordance with those from the Health, Aging and Body Composition (Health ABC) study $(\mathrm{N}=2488)$ [17], which found associations between higher arterial stiffness, as measured by PWV, and more rapid cognitive decline, as measured by MMSE over nine years of follow-up. Additionally, previous results from a sub sample $(\mathrm{N}=552)$ [18] of older adults in Health $\mathrm{ABC}$ found an association between higher PWV and greater cognitive decline on the psychomotor speed only but not on tests of memory and global cognitive function. Furthermore, findings from Baltimore Longitudinal Study of Aging (BLSA) $(\mathrm{N}=582)$ [19] showed significant associations between higher PWV and more rapid cognitive decline on the Blessed Information Memory Concentration Test (working memory test). However, results from the BLSA study did not provide evidence for an association between PWV and tests of global cognitive function [19]. In contrast to our findings, PWV did not predict cognitive decline between two time points over an average of 5 years in the Rotterdam Study [23].

The inconsistency of results across studies may due to differences in aspects of study design, including the specific neuropsychological tests used, sample size of the study, and differences in participant's characteristics. Many studies used MMSE to assess cognitive impairments 
in adults. It has been suggested that MMSE is not a suitable measure for cognitive function among healthy participants due to the ceiling effect. Moreover, MMSE is insensitive to small changes in cognitive function [24]. The sample size is crucial to provide adequate statistical power. Previous studies of the association of arterial stiffness measured by PWV with cognitive decline had fewer than 500 participants.

Our study is the first population-based study to examine the association between arterial stiffness and cognitive decline in a large prospective cohort study of British civil servants who underwent three repeated cognitive assessment over 7 years of follow-up. The PWV is regarded as the gold standard for measuring arterial stiffness and thus provides a great strength to our study. We examined the influence of arterial stiffness on different aspects of cognitive functioning rather than assessing general impairment with a widely used tool for assessing cognitive mental status such as MMSE. A battery of cognitive tests used in this study is a better measure for capturing variability in cognitive scores. The estimates did not change when the analyses were repeated using inverse probability weights showing that our results are less likely to be affected by attrition bias. Our study also has several limitations, the data derived from white-collar civil servants and may not be the representative of general populations. Given the longitudinal nature of the study, mortality or other competing risks may have resulted in an attenuation of our results. Our study has limitations. Cognitive data derived from generally healthy, retired white-collar civil servants may not be broadly representative. Cognitive decline may be slower than among the general population, and this phenomenon may help to explain why we did not observe a clear link between aortic stiffness and change in AH4-I score.

In conclusion, our results indicate that high arterial stiffness is associated with accelerated decline in global cognitive score. Among the domains, decline in phonemic fluency was most clearly linked to stiffness of the aorta. We showed that executive function could be at risk of impairment due to reduced aortic compliance and loss of elasticity. Future studies need to determine if the interventions on reducing or preventing arterial stiffness can be effective in delaying cognitive decline.

Acknowledgements The Whitehall II study has been supported by Grants K013351, R024227, and S011676 from the UK Medical Research Council (MRC); Grants PG/11/63/29011 and RG/13/2/30098 from the British Heart Foundation; funding from the British Health and Safety Executive; the British Department of Health; Grant R01HL036310 from the National Heart, Lung, and Blood Institute; Grants R01AG056477 and R01AG034454 from the National Institute on Aging; and Grant ES/J023299/1 from the Economic and Social Research Council. MK was supported by NordFork, the MRC, the Academy of Finland (311492) and Helsinki Institute of Life Science.
Open Access This article is distributed under the terms of the Creative Commons Attribution 4.0 International License (http://creativecommons.org/licenses/by/4.0/), which permits unrestricted use, distribution, and reproduction in any medium, provided you give appropriate credit to the original author(s) and the source, provide a link to the Creative Commons license, and indicate if changes were made.

\section{References}

1. Rizzi L, Rosset I, Roriz-Cruz M. Global epidemiology of dementia: Alzheimer's and vascular types. Biomed Res Int. 2014;2014:908915. https://doi.org/10.1155/2014/908915.

2. Guzman-Castillo M, Ahmadi-Abhari S, Bandosz P, Capewell S, Steptoe A, Singh-Manoux A, Kivimaki M, Shipley MJ, Brunner EJ, O'Flaherty M. Forecasted trends in disability and life expectancy in England and Wales up to 2025: a modelling study. Lancet Public Health. 2017;2(7):e307-13. https://doi.org/10.1016/ S2468-2667(17)30091-9.

3. Ahmadi-Abhari S, Guzman-Castillo M, Bandosz P, Shipley MJ, Muniz-Terrera G, Singh-Manoux A, Kivimaki M, Steptoe A, Capewell S, O'Flaherty M, Brunner EJ. Temporal trend in dementia incidence since 2002 and projections for prevalence in England and Wales to 2040: modelling study. Bmj-Brit Med J. 2017. https://doi.org/10.1136/bmj.j2856.

4. Brunner EJ, Shipley MJ, Ahmadi-Abhari S, Tabak AG, McEniery CM, Wilkinson IB, Marmot MG, Singh-Manoux A, Kivimaki M. Adiposity, obesity, and arterial aging: longitudinal study of aortic stiffness in the Whitehall II cohort. Hypertension. 2015;66(2):294-300. https://doi.org/10.1161/HYPER TENSIONAHA.115.05494.

5. McEniery CM, Wilkinson IB, Johansen NB, Witte DR, SinghManoux A, Kivimaki M, Tabak AG, Brunner EJ, Shipley MJ. Nondiabetic glucometabolic status and progression of aortic stiffness: the Whitehall II study. Diabetes Care. 2017;40(4):599_ 606. https://doi.org/10.2337/dc16-1773.

6. Ahmadi-Abhari S, Sabia S, Shipley MJ, Kivimaki M, SinghManoux A, Tabak A, McEniery C, Wilkinson IB, Brunner EJ. Physical activity, sedentary behavior, and long-term changes in aortic stiffness: the Whitehall II study. J Am Heart Assoc. 2017. https://doi.org/10.1161/jaha.117.005974.

7. Okamoto M, Shipley MJ, Wilkinson IB, McEniery CM, Valencia-Hernandez CA, Singh-Manoux A, Kivimaki M, Brunner EJ. Does poorer pulmonary function accelerate arterial stiffening?: a cohort study with repeated measurements of carotid-femoral pulse wave velocity. Hypertension. 2019;74(4):929-35. https:// doi.org/10.1161/HYPERTENSIONAHA.119.13183.

8. Palombo C, Kozakova M. Arterial stiffness, atherosclerosis and cardiovascular risk: pathophysiologic mechanisms and emerging clinical indications. Vasc Pharmacol. 2016;77:1-7. https:// doi.org/10.1016/j.vph.2015.11.083.

9. Li X, Lyu P, Ren Y, An J, Dong Y. Arterial stiffness and cognitive impairment. J Neurol Sci. 2017;380:1-10. https://doi. org/10.1016/j.jns.2017.06.018.

10. Laurent S, Cockcroft J, Van Bortel L, Boutouyrie P, Giannattasio C, Hayoz D, Pannier B, Vlachopoulos C, Wilkinson I, Struijker-Boudier H. European network for non-invasive investigation of large. A expert consensus document on arterial stiffness: methodological issues and clinical applications. Eur Heart J. 2006;27(21):2588-605. https://doi.org/10.1093/eurhe artj/ehl254.

11. Lim SL, Gao Q, Nyunt MS, Gong L, Lunaria JB, Lim ML, Ling A, Lam CS, Richards AM, Ling LH, Ng TP. Vascular health indices and cognitive domain function: Singapore longitudinal 
ageing studies. J Alzheimers Dis. 2016;50(1):27-40. https://doi. org/10.3233/JAD-150516.

12. Pase MP, Himali JJ, Mitchell GF, Beiser A, Maillard P, Tsao C, Larson MG, DeCarli C, Vasan RS, Seshadri S. Association of aortic stiffness with cognition and brain aging in young and middle-aged adults: the Framingham third generation cohort study. Hypertension. 2016;67(3):513-9. https://doi.org/10.1161/ HYPERTENSIONAHA.115.06610.

13. Riba-Llena I, Nafria C, Filomena J, Tovar JL, Vinyoles E, Mundet X, Jarca CI, Vilar-Bergua A, Montaner J, Delgado P. High daytime and nighttime ambulatory pulse pressure predict poor cognitive function and mild cognitive impairment in hypertensive individuals. J Cereb Blood Flow Metab. 2016;36(1):253-63. https ://doi.org/10.1038/jcbfm.2015.90.

14. Sugawara N, Yasui-Furukori N, Umeda T, Kaneda A, Sato Y, Takahashi I, Matsuzaka M, Danjo K, Nakaji S, Kaneko $\mathrm{S}$. Comparison of ankle-brachial pressure index and pulse wave velocity as markers of cognitive function in a community-dwelling population. BMC Psychiatry. 2010. https://doi. org/10.1186/1471-244x-10-46.

15. Pase MP, Beiser A, Himali JJ, Tsao C, Satizabal CL, Vasan RS, Seshadri S, Mitchell GF. Aortic stiffness and the risk of incident mild cognitive impairment and dementia. Stroke. 2016;47(9):2256-61. https://doi.org/10.1161/STROK EAHA.116.013508.

16. Taniguchi Y, Fujiwara Y, Nofuji Y, Nishi M, Murayama H, Seino S, Tajima R, Matsuyama Y, Shinkai S. Prospective study of arterial stiffness and subsequent cognitive decline among communitydwelling older Japanese. J Epidemiol. 2015;25(9):592-9. https:// doi.org/10.2188/jea.JE20140250.

17. Zeki Al Hazzouri A, Newman AB, Simonsick E, Sink KM, Sutton Tyrrell K, Watson N, Satterfield S, Harris T, Yaffe K, Health ABCS. Pulse wave velocity and cognitive decline in elders: the health, aging, and body composition study. Stroke. 2013;44(2):388-93. https://doi.org/10.1161/strokeaha.112.67353 3.

18. Watson NL, Sutton-Tyrrell K, Rosano C, Boudreau RM, Hardy SE, Simonsick EM, Najjar SS, Launer LJ, Yaffe K, Atkinson HH, Satterfield S, Newman AB. Arterial stiffness and cognitive decline in well-functioning older adults. J Gerontol A Biol Sci Med Sci. 2011;66(12):1336-42. https://doi.org/10.1093/gerona/glr119.

19. Waldstein SR, Rice SC, Thayer JF, Najjar SS, Scuteri A, Zonderman AB. Pulse pressure and pulse wave velocity are related to cognitive decline in the Baltimore longitudinal study of aging. Hypertension. 2008;51(1):99-104. https://doi.org/10.1161/ HYPERTENSIONAHA.107.093674.

20. Meyer ML, Palta P, Tanaka H, Deal JA, Wright J, Knopman DS, Griswold ME, Mosley TH, Heiss G. Association of central arterial stiffness and pressure pulsatility with mild cognitive impairment and dementia: the atherosclerosis risk in communities study-neurocognitive study (ARIC-NCS). J Alzheimers Dis. 2017;57(1):195-204. https://doi.org/10.3233/JAD-161041.

21. Gustavsson AM, Stomrud E, Abul-Kasim K, Minthon L, Nilsson PM, Hansson O, Nagga K. Cerebral microbleeds and white matter hyperintensities in cognitively healthy elderly: a cross-sectional cohort study evaluating the effect of arterial stiffness. Cerebrovasc Dis Extra. 2015;5(2):41-51. https://doi.org/10.1159/000377710.

22. Singer J, Trollor JN, Crawford J, O'Rourke MF, Baune BT, Brodaty H, Samaras K, Kochan NA, Campbell L, Sachdev PS, Smith E. The association between pulse wave velocity and cognitive function: the Sydney memory and ageing study. PLoS ONE. 2013. https://doi.org/10.1371/journal.pone.0061855.

23. Poels MM, van Oijen M, Mattace-Raso FU, Hofman A, Koudstaal PJ, Witteman JC, Breteler MM. Arterial stiffness, cognitive decline, and risk of dementia: the Rotterdam study. Stroke.
2007;38(3):888-92. https://doi.org/10.1161/01.STR.0000257998 .33768.87.

24. Mitchell AJ. A meta-analysis of the accuracy of the mini-mental state examination in the detection of dementia and mild cognitive impairment. J Psychiatr Res. 2009;43(4):411-31. https://doi. org/10.1016/j.jpsychires.2008.04.014.

25. Sommerlad A, Sabia S, Singh-Manoux A, Lewis G, Livingston G. Association of social contact with dementia and cognition: 28-year follow-up of the Whitehall II cohort study. PLoS Med. 2019;16(8):e1002862. https://doi.org/10.1371/journ al.pmed.1002862.

26. Sabia S, Dugravot A, Dartigues JF, Abell J, Elbaz A, Kivimaki M, Singh-Manoux A. Physical activity, cognitive decline, and risk of dementia: 28 year follow-up of Whitehall II cohort study. BMJ. 2017;357:j2709. https://doi.org/10.1136/bmj.j2709.

27. Seaman SR, White IR. Review of inverse probability weighting for dealing with missing data. Stat Methods Med Res. 2013;22(3):278-95. https://doi.org/10.1177/0962280210395740.

28. Mitchell GF. Effects of central arterial aging on the structure and function of the peripheral vasculature: implications for end-organ damage. J Appl Physiol (1985). 2008;105(5):1652-60. https://doi. org/10.1152/japplphysiol.90549.2008.

29. Henskens LHG, Kroon AA, van Oostenbrugge RJ, Gronenschild EHBM, Fuss-Lejeune MMJJ, Hofman PAM, Lodder J, de Leeuw $\mathrm{PW}$. Increased aortic pulse wave velocity is associated with silent cerebral small-vessel disease in hypertensive patients. Hypertension. 2008;52(6):1120-U72. https://doi.org/10.1161/Hypertensi onaha.108.119024.

30. Iadecola C, Park L, Capone C. Threats to the mind: aging, amyloid, and hypertension. Stroke. 2009;40(3 Suppl):S40-4. https:// doi.org/10.1161/STROKEAHA.108.533638.

31. Nichols WW, Denardo SJ, Davidson JB, Huo TY, Merz CNB, Pepine CJ. Association of aortic stiffness and wave reflections with coronary flow reserve in women without obstructive coronary artery disease: an ancillary study from the National Heart, Lung, and Blood Institute-sponsored Women's Ischemia Syndrome Evaluation (WISE). Am Heart J. 2015;170(6):1243-54. https://doi.org/10.1016/j.ahj.2015.08.019.

32. Mattace-Raso FU, van der Cammen TJ, Hofman A, van Popele NM, Bos ML, Schalekamp MA, Asmar R, Reneman RS, Hoeks AP, Breteler MM, Witteman JC. Arterial stiffness and risk of coronary heart disease and stroke: the Rotterdam study. Circulation. 2006;113(5):657-63. https://doi.org/10.1161/CIRCULATIO NAHA.105.555235.

33. Al-Qazzaz NK, Ali SH, Ahmad SA, Islam S, Mohamad K. Cognitive impairment and memory dysfunction after a stroke diagnosis: a post-stroke memory assessment. Neuropsychiatr Dis Treat. 2014;10:1677-91. https://doi.org/10.2147/NDT.S67184.

34. Nutter-Upham KE, Saykin AJ, Rabin LA, Roth RM, Wishart HA, Pare N, Flashman LA. Verbal fluency performance in amnestic MCI and older adults with cognitive complaints. Arch Clin Neuropsychol. 2008;23(3):229-41. https://doi.org/10.1016/j. acn.2008.01.005.

35. Rinehardt E, Eichstaedt K, Schinka JA, Loewenstein DA, Mattingly M, Fils J, Duara R, Schoenberg MR. Verbal fluency patterns in mild cognitive impairment and Alzheimer's disease. Dement Geriatr Cogn Disord. 2014;38(1-2):1-9. https://doi. org/10.1159/000355558.

36. Newman LM, Trivedi MA, Bendlin BB, Ries ML, Johnson SC. The relationship between gray matter morphometry and neuropsychological performance in a large sample of cognitively healthy adults. Brain Imaging Behav. 2007;1(1-2):3-10. https://doi. org/10.1007/s11682-007-9000-5.

Publisher's Note Springer Nature remains neutral with regard to jurisdictional claims in published maps and institutional affiliations. 